\title{
A saúde bucal na mídia impressa: análise das matérias jornalísticas nos anos de 2004-2009
}

\author{
Oral health in the printed media: \\ analysis of newspaper articles in the years 2004-2009
}

\footnotetext{
Aline Guio Cavaca ${ }^{1}$

Victor Gentilli ${ }^{2}$

Eliana Zandonade ${ }^{3}$

Moacyr Cortellete Júnior ${ }^{4}$

Adauto Emmerich ${ }^{3}$
}

\footnotetext{
${ }^{1}$ Escola Nacional de Saúde Pública. Fundação Oswaldo Cruz. Rua Leopoldo Bulhões 1480, Manguinhos. 21041-210 Rio de Janeiro RJ. alineguica@hotmail.com ${ }^{2}$ Departamento de

Comunicação Social, Centro de Artes, Universidade Federal do Espírito Santo.

${ }^{3}$ Programa de Pósgraduação em Saúde Coletiva, Universidade Federal do Espírito Santo. ${ }^{4}$ Engenharia da Computação, Universidade Federal do Espirito Santo.
}

\begin{abstract}
This study seeks to outline the main characteristics of the texts on oral health that appeared in the printed media in the State of Espirito Santo from 2004 to 2009, in order to analyze and compare the issues, approaches and journalistic relevance related to the theme prioritized in A Tribuna and A Gazeta newspapers. Exploratory documentary research was conducted, based on quantitative content analysis of the material, which established that the issues included ranged from information about oral health policies, community service and prevention of oral health diseases, to the "aesthetic tendencies" of the smile. It also covered the dissemination of new technologies and dental specialties and there was a predominance of even-numbered pages, fewer first page texts and full-page coverage. This implies a moderate appreciation of these issues, different editorial projects, plus the difference in target audience that determined the journalistic standard and the predominance of specialized sources. Despite the oral health articles not revealing journalistic "scoops", they can be reworked using conscious journalistic techniques, in order to elicit the extraordinary from the ordinary, giving rise to texts of social relevance in both newspapers.
\end{abstract}

Key words Oral health, Health communication, Mass media, Public health
Resumo Este estudo objetiva delinear as principais características das matérias sobre saúde bucal veiculadas na mídia impressa do Espírito Santo de 2004 a 2009, a fim de analisar e comparar os assuntos, as abordagens e a relevância jornalística relacionadas à temática priorizados pelos jornais $\boldsymbol{A}$ Tribuna e $\boldsymbol{A}$ Gazeta. Foi realizada uma pesquisa exploratória documental, a partir da análise de conteúdo categorial quantitativa das matérias, a qual permitiu constatar que: os assuntos abordados compreenderam desde informações sobre políticas de saúde bucal, serviços prestados à comunidade e prevenção às doenças bucais, até as "tendências estéticas" do sorriso, a divulgação de novas tecnologias e de especialidades odontológicas; houve um predominio de páginas pares, poucas chamadas na primeira página e a veiculação em página inteira, o que significa uma valorização moderada desses assuntos; os projetos editoriais distintos, aliados à diferença de público alvo determinaram o padrão jornalistico e houve o predomínio de fonte especialista. Apesar das matérias de saúde bucal não apresentarem 'furos' jornalísticos, podem ser trabalhadas, através de uma prática jornalística consciente, de maneira a evocar o extraordinário do ordinário, dando origem a matérias com relevância social em ambos os periódicos.

Palavras-chave Saúde bucal, Comunicação em saúde, Saúde pública 


\section{Introdução}

A saúde bucal é entendida como o estado de harmonia, normalidade ou higidez da boca. Representa um conjunto de condições objetivas (biológicas) e subjetivas (psicológicas), que possibilita o exercício de funções, como fonação, deglutição e mastigação. Além disso, a dimensão estética inerente à região anatômica permite o exercício da autoestima e do relacionamento social ${ }^{1,2}$. A maneira como a população percebe a saúde bucal pode ser influenciada ou "construída" pela mídia, uma vez que concebe um campo de força e espaço de sociabilidade com profundas repercussões nas ações políticas e nos processos sociais de interação e interlocução entre indivíduos e grupos ${ }^{3}$.

Segundo dados divulgados do levantamento epidemiológico em saúde bucal no Brasil, em 2010, o país avançou em relação às condições de saúde bucal da população, entrando no grupo de países com baixa prevalência de cáries, havendo redução expressiva de $26 \%$ do CPO-D (indicador que mensura a soma dos dentes cariados, perdidos e obturados) em crianças de até 12 anos, $30 \%$ em adolescentes de 15-19 anos e 19\% em adultos de 35-44 anos, nos últimos sete anos. Porém, os flagelos sociais históricos continuam representados nos números que indicam a desigualdade regional de situação de saúde bucal (os valores extremos entre Norte e Sudeste mostram uma diferença de quase $90 \%$ no CPOD em crianças de até 12 anos) e no edentulismo, repercutindo na necessidade de prótese total de mais de três milhões de idosos e de prótese parcial em mais outros quatro milhões ${ }^{4}$. Dessa forma, a mídia, como lugar privilegiado de produção e reprodução do real, com forte influência cultural, pode contextualizar uma divulgação desses dados de forma "positiva", ressaltando os avanços, ou provocar uma reflexão consciente através da problematização dos desafios a serem enfrentados.

A Saúde Bucal Coletiva representa um campo de conhecimentos e práticas que integra a Saúde Coletiva, em consonância com os princípios do Sistema Único de Saúde (SUS), que incorpora e redefine o campo da Odontologia. Contrapõese, portanto, à Odontologia de mercado, liberalprivatista, a qual se caracteriza pela mercantilização dos serviços odontológicos, pela manutenção do monopólio do acesso aos recursos odontológicos pelas elites e pelo enfoque biológicocurativista. Assim, representa uma referência de uma práxis capaz de recuperar para o trabalho em Odontologia suas dimensões política, social, comunitária, preventiva e integral, indispensá- veis às práticas de saúde pautadas na democracia $^{1,5}$. Neste sentido, valoriza a promoção da saúde bucal como uma ação que objetiva diminuir as diferenças no estado de saúde e assegurar a igualdade de oportunidades, promovendo os meios que permitam a toda população desenvolver ao máximo sua saúde em potencial, através, dentre outras coisas, da oferta de acesso à educação e informação em saúde ${ }^{6}$.

Nota-se que a questão da educação em saúde está fortemente atrelada às instituições escolares e da própria saúde, porém, os meios de comunicação representam um importante instrumento pedagógico, uma vez que podem atingir um grande número de pessoas ao mesmo tempo ${ }^{7}$. Além disso, a "realidade odontológica" relativa à cobertura assistencial, à divulgação científica de novidades tecnológicas, ao quadro epidemiológico da população, entre outras, nos são apresentados, na maioria das vezes, por meio da divulgação midiática.

Nesse sentido, as informações jornalísticas são reconhecidas como de suma importância para suprir a necessidade social da informação, oferecendo visibilidade ao poder e ao mundo e fomentando o exercício da cidadania ${ }^{8}$. De acordo com a hipótese do agenda-setting, a mídia possui a capacidade de agendamento, ou seja, os temas apresentados pela mídia determinam a presença - ou não - dos mesmos na pauta de interesse das pessoas. Assim, a sociedade tende a atribuir valor e a incluir ou excluir do seu próprio conhecimento aquilo que os meios de comunicação de massa incluem ou excluem de seu conteúdo, definindo, também, a hierarquia de importância e prioridade desses assuntos em relação a outros de acordo com sua disposição nos meios ${ }^{9,10}$.

Entende-se que os jornais são os principais promotores da agenda do público, pois definem amplamente o seu âmbito de interesse ${ }^{9}$. Enfim, de acordo com esta hipótese, a mídia tem maior capacidade de priorizar assuntos do que influenciar a opinião sobre eles. Sendo assim, o estudo da mídia impressa torna-se um importante instrumento para o vislumbre da priorização e da abordagem dos assuntos de interesse da sociedade.

No Espírito Santo (ES), existem dois jornais de grande circulação e impacto em todo o estado, com projetos editoriais, públicos-alvo e preços diferentes: A Tribuna e A Gazeta. O jornal A Tribuna foi fundado em 22 de setembro de 1938, na cidade de Vitória, capital do ES. Possui formato tablóide ( $38 \mathrm{~cm} \times 30 \mathrm{~cm}$ ), em cores, com o público-alvo das classes $\mathrm{C}, \mathrm{D}$ e E, sendo líder em circulação no $\mathrm{ES}^{11}$. Já o jornal A Gazeta é o mais 
antigo periódico em circulação no estado, apresenta-se em formato gráfico standard (entre $60 \mathrm{~cm}$ x $38 \mathrm{~cm}$ e $75 \mathrm{~cm}$ x $60 \mathrm{~cm}$ ), com linha editorial conservadora, atingindo um público com perfil elitista, $65 \%$ homens e $35 \%$ mulheres, com idade entre 20 e 49 anos, focado nas classes AB e C1 e é líder em assinaturas ${ }^{12,13}$. Os dois periódicos possuem projetos editoriais e público-alvo diferentes. Portanto, supõe-se que tenham distintas abordagens da temática saúde bucal.

Por fim, entende-se que a comunicação em saúde bucal na mídia, além de pautar a temática na sociedade, atua como um instrumento de educação e de promoção da saúde. Porém, percebese que o potencial pedagógico do jornal, quanto à saúde bucal, está sendo subutilizado pela mídia $^{7,14,15}$. Dessa forma, este estudo visa delinear as principais características das matérias sobre saúde bucal veiculadas na mídia impressa do ES, no período de julho de 2004 a junho de 2009, a fim de analisar e comparar os assuntos, as abordagens e a relevância jornalística, relacionadas à temática, priorizadas pelos dois principais jornais do estado.

\section{Metodologia}

Desenvolveu-se uma pesquisa exploratória documental, com abordagem quantitativa, na qual o material pesquisado foi composto por todas as matérias relacionadas à saúde bucal veiculadas no período de março de 2004 a junho de 2009, nos jornais A Gazeta e A Tribuna. O período selecionado de cinco anos permite a verificação do panorama de noticiabilidade da saúde bucal e corresponde a um período de grandes investimentos na área no Brasil, culminando com o desenvolvimento da Política Nacional de Saúde Bucal (Brasil Sorridente) do governo federal, iniciado no ano de 2004 e desenvolvido até os dias de hoje $\mathrm{e}^{16}$.

Foi realizado um levantamento retrospectivo das matérias jornalísticas (excluída a publicidade e a propaganda) que apresentavam em seu conteúdo as palavras-chave: Dentista, Odontologia e Saúde Bucal. Foram descartadas da análise as matérias relacionadas ao vestibular, aos concursos, às propagandas e às questões não-profissionais relacionadas a um determinado profissional da área, devido à irrelevância em relação ao problema de estudo. Portanto, estudou-se apenas o material jornalístico relativo ao escopo do trabalho.

Para a coleta de dados do jornal A Tribuna, foi utilizado o banco de dados digital fornecido pelo jornal, e a seleção das notícias foi feita através de um Programa de Busca Inteligente, desenvolvido pelo Laboratório de Recuperação Inteligente da Informação da UFES, o qual utiliza a busca de informações baseada não apenas em palavras-chave, mas considerando a semântica subjacente à consulta feita pelo usuário, resgatando a informação através de aproximações sucessivas, o que facilita o processo de busca ${ }^{17}$. As matérias do jornal A Gazeta foram selecionadas através de programa de busca do próprio jornal, realizado através da busca pelas palavraschave correspondentes à temática. As notícias foram disponibilizadas em formato impresso, mediante pagamento de taxa por notícia.

$\mathrm{Na}$ quantificação dos dados, foi utilizada a análise de conteúdo categorial quantitativa ${ }^{18}$. Trata-se de uma técnica utilizada para detectar tendências e modelos na análise de critérios de noticiabilidade, enquadramentos e agendamentos, além de descrever e classificar produtos, gêneros, formatos e comparar o conteúdo jornalístico de diferentes mídias ${ }^{19}$. O levantamento foi registrado a partir do preenchimento de uma ficha de identificação, e as matérias foram classificadas de acordo com: o número da matéria, a data, o jornal, o caderno ou a editoria e a página (par, ímpar ou dupla) em que ela foi veiculada; a hierarquia da matéria; a presença de elementos de edição (chamadas de primeira página, fotos, boxes, infográficos, tabelas); o assunto abordado e seu enfoque; a (as) fonte(s) citada(s); a referência à fundamentação científica na matéria; a linguagem utilizada; a presença de termos técnicos e a referência a iniciativas capixabas. As variáveis foram computadas num banco de dados no programa SPSS 16.0 for Windows e o tratamento dos dados foi por análise descritiva e inferencial com cálculos de frequências relativa e absoluta e aplicação dos testes de qui-quadrado, adotando um nível de significância de 5\%.

A confiabilidade do processo de classificação foi avaliada através da codificação em duplicata de uma amostra de $10 \%$ das matérias pesquisadas. Dessa forma, as matérias foram selecionadas através de uma tabela de números aleatórios e classificadas distintivamente por dois pesquisadores, uma cirurgiã-dentista e um jornalista, com posterior confronto dos pareceres. A concordância foi medida por meio do teste estatístico Kappa, tendo apresentado o grau de concordância abaixo do limite aceitável $(\mathrm{K}<0,7)$ apenas na categoria "uso de termos técnicos" e em cinco categorias de classificação de assunto, sendo que tais aspectos foram discutidos em busca 
de consenso. Assim, a confiabilidade não foi comprometida.

A pesquisa foi aprovada pelo Comitê de Ética em pesquisa do Centro de Ciências da Saúde da UFES e foi concedida autorização formal dos jornais selecionados para realização da pesquisa.

\section{Resultados}

Foram selecionadas 392 matérias nos jornais $A$ Gazeta e A Tribuna. Destas amostras, oito textos do jornal A Gazeta eram, na verdade, publicidade, embora usassem tipologia assemelhada à editorial e aparentassem notícias jornalísticas. Vale observar que a forma com que o texto foi apresentado induziam o leitor a equívocos. Dessa forma, estas matérias foram excluídas do universo selecionado, o qual foi composto então por 170 matérias de A Gazeta e 214 matérias de A Tribu$n a$, perfazendo um total de 384 matérias.

A distribuição temporal das matérias ao longo do período selecionado, conforme representado na Figura 1, demonstra que em maio 2005 houve um pico, ou seja, foi nesta data que teve maior publicação de matérias relacionadas à Odontologia em ambos os jornais. Em dezembro de 2004, novembro de 2007 e janeiro de 2008 foram os meses que os jornais menos divulgaram matérias relacionadas ao assunto. As demais

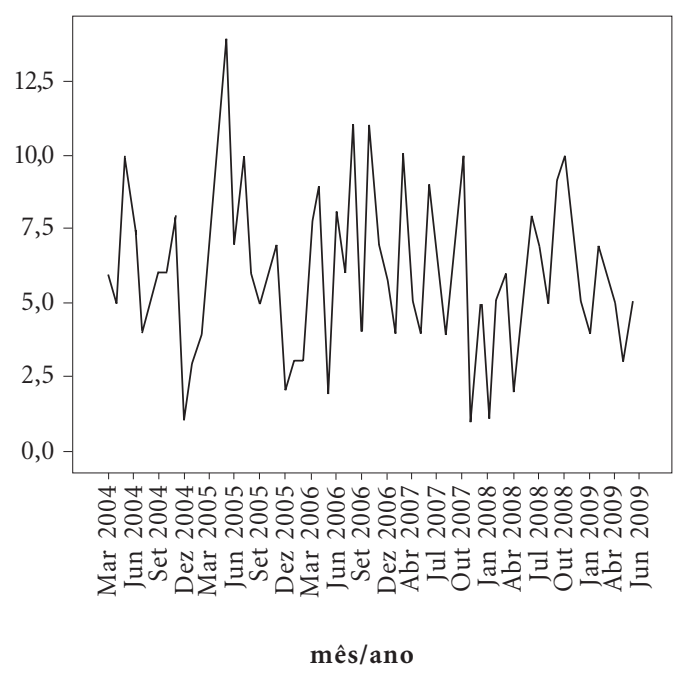

Figura 1. Distribuição temporal das matérias de saúde bucal no período de março de 2004 a junho de 2009 nos jornais A Gazeta e A Tribuna no estado do Espírito Santo - Brasil. publicações variaram entre duas e onze matérias por mês ao longo do período estudado.

Em relação à disposição espacial da matéria, há predominância das páginas pares em ambos os periódicos (49,4\% A Gazeta e 57\% A Tribu$n a)$. Os dois jornais apresentam baixo percentual de chamada na primeira página com as palavras-chave selecionadas (2,9\% A Gazeta e 4,7\% A Tribuna) e, uma porcentagem ainda menor de edições apresentou fotos e infográficos nessas capas ( $1,2 \%$ e $2,3 \%$ respectivamente).

Observa-se na Tabela 1 que quanto ao dia da semana, houve diferença estatística entre os jornais ( $\mathrm{p}=0,0001$ ), ou seja, essa diferença apresentada não é devido ao acaso, sendo que, as matérias do jornal A Tribuna encontram-se distribuídas de forma semelhante ao longo da semana, já o jornal A Gazeta concentra mais da metade das matérias relacionadas à temática no domingo. No que se refere ao local da página em que a matéria é veiculada, há diferença estatística que indica um padrão diferenciado entre os dois jornais, porém nota-se uma predominância de publicação na página inteira em ambos $(34,7 \% \mathrm{~A}$ Gazeta e 33,2\% A Tribuna).

No que tange ao gênero jornalístico das matérias estudadas, são predominantes as notícias, as reportagens e a presença do jornalismo de serviço na abordagem das matérias, tendo diferença estatística com relação ao jornal publicado ( $\mathrm{p}$ $=0,0020$ ), ou seja, o tipo de gênero utilizado em ambos os jornais não são semelhantes.

Em relação à presença de elementos de edição nas matérias selecionadas, houve diferença estatística entre os dois jornais no que diz respeito à presença de ilustração $(\mathrm{p}=0,0361)$, tabela/box $(\mathrm{p}=0,0307)$ e à matéria ser assinada ou não assinada $(\mathrm{p}=0,0000)$. Dessa forma, o jornal $A$ Tribuna apresenta maior porcentagem de ilustração $(7,9 \%)$ e de tabela/box $(40,7 \%)$ em suas matérias. Já o jornal A Gazeta possui maior número de matérias assinadas $(65,9 \%)$. Em relação à apresentação de fotografias, o percentual foi semelhante nos dois periódicos $(57,1 \%$ em $A$ Gazeta e 57,9\% em A Tribuna). Já gráficos e infográficos foram presentes poucas vezes em ambos ( $1,2 \%$ e $5,9 \%$ respectivamente em A Gazeta e $0,5 \%$ e $4,2 \%$ respectivamente em A Tribuna).

Ao se explorar a fundamentação científica citada na matéria, não foi verificada diferença estatística entre os dois jornais ( $\mathrm{p}=0,3555)$, sendo que $20 \%$ das matérias de $A$ Gazeta e $16,4 \%$ de $A$ Tribuna fizeram menção a algum estudo científico ou dados estatísticos em seu conteúdo. A linguagem utilizada foi classificada como com- 
Tabela 1. Análise bivariada pelo teste de qui-quadrado para variáveis relacionadas às características hierárquicas entre os jornais A Gazeta e A Tribuna, Espírito Santo - Brasil, 2004-2009.

\begin{tabular}{|c|c|c|c|c|c|c|}
\hline \multirow[b]{2}{*}{ Variável } & \multirow[b]{2}{*}{ Categoria } & \multicolumn{2}{|c|}{ A Gazeta } & \multicolumn{2}{|c|}{ A Tribuna } & \multirow[b]{2}{*}{ p-valor } \\
\hline & & $n=170$ & $\%$ & $\mathrm{~N}=214$ & $\%$ & \\
\hline \multirow[t]{7}{*}{ Dia } & Segunda-feira & 19 & 11,2 & 11 & 5,1 & 0,0001 \\
\hline & Terça-feira & 14 & 8,2 & 26 & 12,1 & \\
\hline & Quarta-feira & 9 & 5,3 & 26 & 12,1 & \\
\hline & Quinta-feira & 12 & 7,1 & 33 & 15,4 & \\
\hline & Sexta-feira & 6 & 3,5 & 27 & 12,6 & \\
\hline & Sábado & 12 & 7,1 & 26 & 12,1 & \\
\hline & Domingo & 98 & 57,6 & 65 & 30,4 & \\
\hline \multirow{6}{*}{$\begin{array}{l}\text { Local de } \\
\text { publicação na } \\
\text { página }\end{array}$} & Superior direita & 33 & 19,4 & 27 & 12,6 & 0,0269 \\
\hline & Inferior direita & 31 & 18,2 & 30 & 14,0 & \\
\hline & Superior esquerda & 30 & 17,6 & 38 & 17,8 & \\
\hline & Inferior esquerda & 11 & 6,5 & 33 & 15,4 & \\
\hline & Central & 6 & 3,5 & 15 & 7,0 & \\
\hline & Página inteira & 59 & 34,7 & 71 & 33,2 & \\
\hline \multirow[t]{13}{*}{ Gênero } & Notícia & 56 & 32,9 & 67 & 31,3 & 0,0020 \\
\hline & Artigo de opinião & 13 & 7,6 & 10 & 4,7 & \\
\hline & Crônica & 1 & 0,6 & 0 & 0,0 & \\
\hline & Entrevista & 1 & 0,6 & 0 & 0,0 & \\
\hline & Coluna de notas & 6 & 3,5 & 4 & 1,9 & \\
\hline & Coluna de texto & 0 & 0,0 & 2 & 0,9 & \\
\hline & Reportagem & 25 & 14,7 & 47 & 22,0 & \\
\hline & Jornalismo de serviço & 56 & 32,9 & 41 & 19,2 & \\
\hline & Notícia + coluna de notas & 1 & 0,6 & 8 & 3,7 & \\
\hline & Notícia + jornalismo de serviço & 2 & 1,2 & 2 & 0,9 & \\
\hline & Entrevista + jornalismo de serviço & 2 & 1,2 & 2 & 0,9 & \\
\hline & Coluna de texto + reportagem & 0 & 0,0 & 1 & 0,5 & \\
\hline & Reportagem + jornalismo de serviço & 7 & 4,1 & 30 & 14,0 & \\
\hline \multirow[t]{2}{*}{ Matéria Assinada } & Sim & 112 & 65,9 & 77 & 36,0 & 0,0001 \\
\hline & Não & 58 & 34,1 & 137 & 64,0 & \\
\hline Uso de termos & Sim, sem explicação & 13 & 7,6 & 8 & 3,7 & 0,0006 \\
\hline \multirow[t]{2}{*}{ Técnicos } & Sim, com explicação & 65 & 38,2 & 50 & 23,4 & \\
\hline & Não & 92 & 54,1 & 156 & 72,9 & \\
\hline Referência a & Sim, pesquisa & 10 & 5,9 & 8 & 3,7 & 0,1608 \\
\hline Iniciativas & Sim, serviço & 46 & 27,1 & 76 & 35,5 & \\
\hline Capixabas & Não & 114 & 67,1 & 130 & 60,7 & \\
\hline
\end{tabular}

preensível ao leitor leigo para $98,8 \%$ das matérias de $A$ Gazeta e $97,7 \%$ das matérias de $A$ Tribuna. Houve predominância de matérias de origem local em ambos os veículos (95,3\% A Gazeta e 93\% A Tribuna) em detrimento a matérias de origem nacional ou internacional.

O uso de termos técnicos apresentou diferença estatística entre os dois periódicos ( $\mathrm{p}=$ 0,0006), sendo que no jornal A Gazeta estes foram citados com maior frequência, acompanha- dos de explicações de seus significados $(38,2 \%$ enquanto o jornal $A$ Tribuna apresentava 23,4\%) como ausente de explicações (7,6 \% contra 3,7\% de A Tribuna). Foram mencionadas referências às iniciativas capixabas na área de saúde bucal em 33\% das matérias de A Gazeta, sendo que em $5,9 \%$ dos casos era citada alguma pesquisa realizada no estado e em $27,1 \%$ dos casos, mencionando algum serviço odontológico ofertado na região. Já o jornal $A$ Tribuna aludiu iniciativas 
capixabas em 39,2 \% de suas matérias, destas $3,7 \%$ eram sobre pesquisas e $35,5 \%$ sobre serviços odontológicos (Tabela 1).

As Tabelas 2 e 3 apresentam a classificação dos assuntos abordados nas matérias de saúde bucal e a forma de abordagem dos mesmos, os quais foram categorizados em: educativo, informativo, marketing (relacionado a alguma men- ção a produtos, marcas ou novas técnicas, profissionais, clínicas odontológicas que sugerem propaganda no corpo da matéria) ou várias abordagens associadas.

A Tabela 2 concentrou os assuntos relacionados ao SUS e à Saúde Bucal Coletiva. Observamos nesta tabela uma diferença estatística entre os jornais quanto à publicação de matérias relacio-

Tabela 2. Análise bivariada pelo teste de qui-quadrado para variáveis relativas dos assuntos de Saúde Bucal Coletiva e o seu enfoque, nos jornais A Gazeta e A Tribuna, Espírito Santo - Brasil, 2004-2009.

\begin{tabular}{|c|c|c|c|c|c|c|}
\hline \multirow[b]{2}{*}{ Variável } & \multirow[b]{2}{*}{ Categoria } & \multicolumn{2}{|c|}{ A Gazeta } & \multicolumn{2}{|c|}{ A Tribuna } & \multirow[b]{2}{*}{ p-valor } \\
\hline & & $\mathbf{n}$ & $\%$ & $\mathbf{n}$ & $\%$ & \\
\hline \multirow{3}{*}{$\begin{array}{l}\text { Odontologia } \\
\text { no SUS }\end{array}$} & Educativo & 5 & 19,2 & 5 & 13,5 & \multirow[t]{3}{*}{0,1738} \\
\hline & Informativo & 19 & 73,1 & 32 & 86,5 & \\
\hline & Educativo + informativo & 2 & 7,7 & 0 & 0,0 & \\
\hline \multirow[t]{4}{*}{ Prevenção } & Educativo & 33 & 73,3 & 13 & 59,1 & \multirow[t]{4}{*}{0,5140} \\
\hline & Informativo & 10 & 22,2 & 8 & 36,4 & \\
\hline & Marketing & 1 & 2,2 & 0 & 0,0 & \\
\hline & Educativo + informativo & 1 & 2,2 & 1 & 4,5 & \\
\hline \multirow[t]{4}{*}{ Doenças bucais } & Educativo & 23 & 79,3 & 30 & 90,9 & \multirow[t]{4}{*}{0,4200} \\
\hline & Informativo & 4 & 13,8 & 3 & 9,1 & \\
\hline & Educativo + informativo & 1 & 3,4 & 0 & 0,0 & \\
\hline & Educativo + informativo + marketing & 1 & 3,4 & 0 & 0,0 & \\
\hline Acesso a & Educativo & 7 & 26,9 & 7 & 11,3 & 0,0489 \\
\hline Tratamento & Informativo & 18 & 69,2 & 55 & 88,7 & \\
\hline Odontológico & Informativo + marketing & 1 & 3,8 & 0 & 0,0 & \\
\hline \multirow{2}{*}{$\begin{array}{l}\text { Políticas de } \\
\text { Saúde }\end{array}$} & Educativo & 7 & 38,9 & 4 & 28,6 & \multirow[t]{2}{*}{0,5421} \\
\hline & Informativo & 11 & 61,1 & 10 & 71,4 & \\
\hline \multirow{3}{*}{$\begin{array}{l}\text { Formação } \\
\text { Profissional }\end{array}$} & Educativo & 0 & 0,0 & 2 & 18,2 & \multirow[t]{3}{*}{0,4321} \\
\hline & Informativo & 5 & 100,0 & 8 & 72,7 & \\
\hline & Educativo + informativo & 0 & 0,0 & 1 & 9,1 & \\
\hline \multirow{2}{*}{$\begin{array}{l}\text { Saúde associada } \\
\text { à saúde bucal }\end{array}$} & Educativo & 26 & 83,9 & 18 & 90,0 & \multirow[t]{2}{*}{0,5346} \\
\hline & Informativo & 5 & 16,1 & 2 & 10,0 & \\
\hline \multirow{6}{*}{$\begin{array}{l}\text { Divulgação de } \\
\text { Iniciativas }\end{array}$} & Educativo & 1 & 3,3 & 8 & 13,8 & \multirow[t]{6}{*}{0,2667} \\
\hline & Informativo & 24 & 80,0 & 42 & 72,4 & \\
\hline & Marketing & 2 & 6,7 & 6 & 10,3 & \\
\hline & Educativo + marketing & 0 & 0,0 & 1 & 1,7 & \\
\hline & Informativo + marketing & 2 & 6,7 & 1 & 1,7 & \\
\hline & Educativo + informativo + marketing & 1 & 3,3 & 0 & 0,0 & \\
\hline $\begin{array}{l}\text { Saúde bucal e } \\
\text { Meio ambiente }\end{array}$ & Educativo & 3 & 100,0 & 0 & 0,0 & - \\
\hline \multirow[t]{2}{*}{ Falsos dentistas } & Educativo & 0 & 0,0 & 2 & 20,0 & \multirow[t]{2}{*}{0,2416} \\
\hline & Informativo & 6 & 100,0 & 8 & 80,0 & \\
\hline
\end{tabular}

Os totais das variáveis são menores do que o tamanho da amostra, pois foram excluídas as respostas que não foram abordados nos assuntos pesquisados. 
nadas ao acesso ao tratamento odontológico ( $\mathrm{p}$ $=0,0489$ ). Nota-se que o jornal $A$ Tribuna veicula um grande quantitativo de matérias sobre esse assunto (62), na sua grande maioria $(88,7 \%)$ através de uma abordagem informativa. As políticas públicas de saúde, a divulgação da odontologia no SUS, a formação profissional em saúde, a divulgação de iniciativas na área odontológica e as matérias relacionadas à atuação de falsos dentis- tas foram abordadas majoritariamente de maneira informativa em ambos os periódicos. Já a prevenção, as doenças bucais, a saúde geral associada à saúde bucal e a relação entre a saúde bucal e o meio ambiente foram abordadas em sua maioria, de maneira educativa.

A Tabela 3 traz os assuntos relacionados à odontologia de mercado e especializada. Verifica-se uma diferença estatística $(\mathrm{p}=0,0030)$ em

Tabela 3. Análise bivariada pelo teste de qui-quadrado para variáveis relativas dos assuntos de Odontologia especializada e o seu enfoque, nos jornais A Gazeta e A Tribuna, Espírito Santo - Brasil, 2004-2009.

\begin{tabular}{|c|c|c|c|c|c|c|}
\hline \multirow[b]{2}{*}{ Variável } & \multirow[b]{2}{*}{ Categoria } & \multicolumn{2}{|c|}{ A Gazeta } & \multicolumn{2}{|c|}{ A Tribuna } & \multirow[b]{2}{*}{ p-valor } \\
\hline & & $\mathbf{n}$ & $\%$ & $\mathbf{n}$ & $\%$ & \\
\hline \multirow[t]{6}{*}{ Estética } & Educativo & 8 & 30,8 & 25 & 73,5 & 0,0030 \\
\hline & Informativo & 9 & 34,6 & 4 & 11,8 & \\
\hline & Marketing & 0 & 0,0 & 2 & 5,9 & \\
\hline & Educativo + informativo & 3 & 11,5 & 0 & 0,0 & \\
\hline & Educativo + marketing & 1 & 3,8 & 2 & 5,9 & \\
\hline & Informativo + marketing & 5 & 19,2 & 1 & 2,9 & \\
\hline \multirow[t]{4}{*}{ Ortodontia } & Educativo & 4 & 57,1 & 8 & 80,0 & 0,3564 \\
\hline & Informativo & 1 & 14,3 & 2 & 20,0 & \\
\hline & Marketing & 1 & 14,3 & 0 & 0,0 & \\
\hline & Informativo + marketing & 1 & 14,3 & 0 & 0,0 & \\
\hline Prótese e & Educativo & 3 & 33,3 & 18 & 69,2 & 0,1422 \\
\hline \multirow[t]{3}{*}{ Implante } & Informativo & 3 & 33,3 & 5 & 19,2 & \\
\hline & Educativo + marketing & 0 & 0,0 & 1 & 3,8 & \\
\hline & Informativo + marketing & 3 & 33,3 & 2 & 7,7 & \\
\hline Pediatria & Educativo & 9 & 100,0 & 4 & 100,0 & - \\
\hline \multirow{3}{*}{$\begin{array}{l}\text { Odontologia } \\
\text { veterinária }\end{array}$} & Educativo & 1 & 20,0 & 0 & 0,0 & 0,5488 \\
\hline & Informativo & 2 & 40,0 & 1 & 100,0 & \\
\hline & Educativo + marketing & 2 & 40,0 & 0 & 0,0 & \\
\hline Outras & Educativo & 6 & 66,7 & 7 & 77,8 & 0,8145 \\
\hline Especialidades & Informativo & 2 & 22,2 & 1 & 11,1 & \\
\hline Odontológicas & Informativo + marketing & 1 & 11,1 & 1 & 11,1 & \\
\hline \multirow{6}{*}{$\begin{array}{l}\text { Novas } \\
\text { tecnologias }\end{array}$} & Educativo & 5 & 26,3 & 8 & 53,3 & 0,3015 \\
\hline & Informativo & 8 & 42,1 & 2 & 13,3 & \\
\hline & Marketing & 1 & 5,3 & 1 & 6,7 & \\
\hline & Educativo + informativo & 0 & 0,0 & 1 & 6,7 & \\
\hline & Educativo + marketing & 1 & 5,3 & 0 & 0,0 & \\
\hline & Informativo + marketing & 4 & 21,1 & 3 & 20,0 & \\
\hline Halitose & Educativo & 1 & 100,0 & 9 & 100,0 & - \\
\hline \multirow[t]{3}{*}{ Outros } & Educativo & 7 & 50,0 & 18 & 45,0 & 0,6530 \\
\hline & Informativo & 6 & 42,9 & 21 & 52,5 & \\
\hline & Marketing & 1 & 7,1 & 1 & 2,5 & \\
\hline
\end{tabular}

Os totais das variáveis são menores do que o tamanho da amostra, pois foram excluídas as respostas que não foram abordados nos assuntos pesquisados. 
relação à veiculação da temática "estética" entre os dois periódicos, uma vez que o jornal A Tribuna abordou o assunto de maneira educativa em 73,5\% de suas publicações, e o jornal A Gazeta priorizou essa abordagem em apenas 30,8\% das matérias.

Em relação à temática prótese e implantes e novas tecnologias odontológicas, o jornal A Tribuna possui uma abordagem principalmente educativa $(69,2 \%$ e $53,3 \%$ respectivamente) e o jornal A Gazeta abordou os assuntos prótese e implantes igualmente de forma educativa $(33,3 \%)$, informativa $(33,3 \%)$ e informativa associada ao marketing $(33,3 \%)$ e as novas tecnologias de maneira prioritariamente informativa $(42,1 \%)$. Os assuntos relacionados à ortodontia, pediatria, halitose e outras especialidades odontológicas apresentaram, prioritariamente, abordagem educativa em ambos os jornais.

Ao se analisar o tipo de editoria que veicula as matérias relacionadas à temática nos jornais selecionados, percebe-se que a preferência de publicação de matérias na Editoria cidades/diaa-dia é idêntica, sendo $36.5 \%$ para A Gazeta e $36.9 \%$ para A Tribuna. O jornal A Gazeta con- centra grande parte de suas publicações relacionadas à temática $(41,2 \%)$ na editoria Leve a Vida/ Revista A.G. Já o jornal A Tribuna apresenta uma editoria destinada à publicação de Ciência e Tecnologia, a qual concentrou 5,6\% das matérias, e o espaço de Reportagens Especiais que apresentou $9,8 \%$ da temática.

Quanto às fontes de informação citadas nas matérias, a Figura 2 revela que há o predomínio de consulta a especialistas em ambos os jornais (52,4\% em A Gazeta e 40,2\% em A Tribuna) e que existe uma porcentagem razoável $(15,9 \% A$ Gazeta e 16,8\% A Tribuna) de consulta a mais de uma fonte de informação nos jornais. Porém, a busca a três fontes distintas ou mais apresentouse pequena (1,2\% para $A$ Gazeta e $4,2 \%$ para $A$ Tribuna).

\section{Discussão}

A essência da atividade jornalística é a sistemática emissão de julgamentos no processo de selecionar, organizar e hierarquizar informações ${ }^{20}$. Existem alguns atributos necessários para se trans-

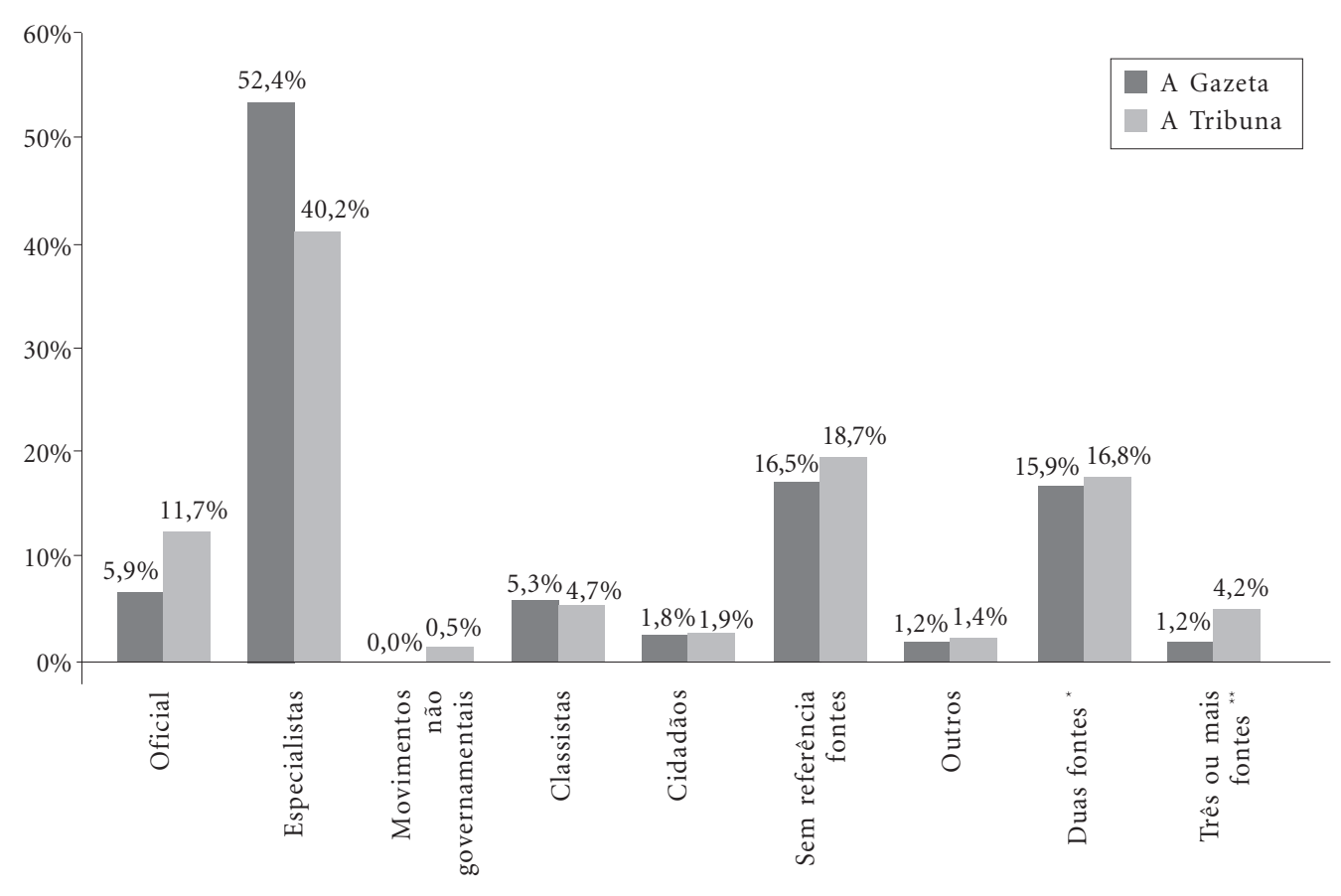

Figura 2. Tipos de fontes segundo os jornais A Gazeta e A Tribuna, Espírito Santo - Brasil, 2004-2009.

*Duas fontes: são quando a matéria apresentava consulta a dois tipos de fonte. ${ }^{* *}$ Três ou mais fontes: são quando a matéria apresentava consulta a três ou mais tipos de fonte. 
formar um fato ordinário do dia-a-dia em uma notícia. Esses atributos, conhecidos como valores-notícias, determinam os critérios de noticiabilidade, os quais definem regras práticas que abrangem um corpus de conhecimentos profissionais que implícita e explicitamente, explicam e guiam os procedimentos operativos redatoriais ${ }^{9}$. De uma forma geral, dizem respeito à proximidade geográfica e cultural do fato; à significatividade e visibilidade; à possibilidade de entreter o público; à repercussão futura e à exclusividade da informação; à hierarquia de poder e prestígio dos acontecimentos e à raridade e atualidade da informação ${ }^{9}$. A escassez de tempo, elemento sempre presente nas rotinas produtivas, acentua a importância desses critérios ${ }^{21}$. Os dados empíricos deste estudo, de uma forma geral, indicam a comprovação destas teorias.

Tradicionalmente, as práticas e as políticas específicas de saúde apresentam-se mescladas ou perpassadas pela contribuição comunicativa ${ }^{22}$. Assim, a comunicação em saúde é entendida como atividades interpessoais ou de comunicação de massa que são direcionadas para melhorar as condições de saúde individuais ou populacionais, sendo uma estratégia fundamental para informar o público sobre as questões de saúde e para manter os problemas de saúde na agenda pública ${ }^{23,24}$. A partir dessa perspectiva, a comunicação é reconhecida como um insumo relevante nos sistemas de saúde, desde a comunicação interpessoal médico-paciente, até a comunicação pública da saúde pela mídia massiva.

Assim como observado na pesquisa de Massuchin e Cervi ${ }^{25}$, a distribuição temporal dos temas estudados apresentou-se em constante oscilação durante o tempo, o que está relacionado mais à presença de acontecimentos específicos durante o período do que à presença constante de debate sobre o assunto no veículo. Assim, o pico de publicações relacionadas à saúde bucal no período de maio de 2005 parece decorrer da divulgação dos resultados relativos à temática, do suplemento de saúde da Pesquisa Nacional por Amostras de Domicílios (PNAD 2003), realizada pelo $\mathrm{IBGE}^{26}$, o qual incitou a editoria dos referidos periódicos a pautar o assunto.

Aliado à capacidade de agendamento, a mídia determina a priorização dos assuntos de acordo com sua disposição nos meios. Portanto, alguns critérios jornalísticos valorizam a matéria, atuando como critérios de hierarquização, como por exemplo: chamada na primeira página; publicação em página ímpar; nas porções superior esquerda e inferior direita; nos finais de semana; presença de elementos de edição e matéria assinada. A temática estudada apresentou-se, majoritariamente, em páginas pares, com poucas chamadas em capas e elementos de edição nas mesmas, o que indica uma valorização restrita por parte dos jornais. Entretanto, apesar de haver um padrão diferenciado de local de publicação nos dois jornais, houve predomínio de publicação em páginas inteiras em ambos, o que demonstra a dedicação de um espaço para apresentação mais aprofundada da temática.

O jornal A Gazeta possui a grande maioria de suas matérias assinadas e utilizou mais termos técnicos em sua escrita, o que condiz com seu projeto editorial, mas também é influenciado pelo tipo de leitor que representa seu público alvo. Além disso, concentrou a maioria de sua publicação sobre a temática no dia de domingo, sendo que $41,2 \%$ de suas publicações são veiculadas numa editoria própria de saúde (Leve a Vida/Revista A.G.), a qual veicula matérias variadas e curiosidades sobre saúde bucal e perguntas de leitores relacionadas à temática, com a resposta de profissionais da especialidade específica. Já o jornal A Tribuna distribuiu suas publicações de forma mais equilibrada em suas editorias, contando inclusive com editorias próprias de Ciência e Tecnologia (a qual veicula, prioritariamente, matérias sobre pesquisas compradas de agências nacionais e internacionais, do tipo: "Extração de dente afeta memória”) e Reportagens Especiais (que fazem reportagens maiores sobre acesso a tratamentos no SUS ou atuação de falsos profissionais no mercado, por exemplo) sugerindo, dessa forma, uma maior produção de noticiário de saúde bucal. Este periódico apresentou também maior porcentagem de figuras e tabela/box em suas edições, recursos atualmente utilizados para dar maior didatismo aos textos, o que demonstra uma valorização do potencial educativo do jornal.

O gênero jornalístico também se mostrou diferente entre os dois jornais, no entanto, é relevante ressaltar que a presença de jornalismo de serviço foi expressiva em ambos. Entende-se por jornalismo de serviço as matérias desenvolvidas para proporcionarem respostas às necessidades de sobrevivência, cultura e conhecimento, fornecendo um serviço aos leitores que buscam orientações para o seu dia-a-dia ${ }^{27}$. Os periódicos utilizam, muitas vezes, elementos de edição, como boxes e infográficos, para veicular esse tipo de informação, como os exemplos seguintes extraídos do estudo: "Algumas dicas de prevenção" ou "Veja aonde encontrar ajuda". Dessa forma, esse 
componente jornalístico potencializa a função educativa da mídia e atua como um instrumento para educação e promoção de saúde bucal.

No que tange à divulgação de iniciativas capixabas relacionadas à saúde bucal, mesmo sendo predominantes as matérias de origem local nos dois periódicos, verifica-se que mais de $60 \%$ das matérias de ambos não fazem nenhum tipo de menção e, quando o fazem, esta é prioritariamente referente a serviços. É compreensível que a própria "oferta" maior de serviços determine um maior espaço de veiculação para tal, porém sabendo da importância da divulgação científica das questões de saúde bucal na mídia, questiona-se: as instituições de pesquisa da área odontológica, e de saúde de uma forma geral, têm oferecido contribuições capazes de estimular e fornecer subsídios para a prática de um jornalismo científico na comunidade em que estão inseridas? Ou ainda: as instituições de ensino superior, os profissionais e os órgãos de saúde têm estimulado a divulgação da temática de saúde bucal na mídia? Tem havido esforços para tornar a saúde bucal interessante para ser noticiada?

Entende-se que, muitas vezes, há uma disjunção entre os critérios valorativos da comunicação e saúde e os interesses jornalísticos ${ }^{28}$. Todavia, é importante que se incentive esse diálogo entre mídia, dentistas e órgãos de saúde, a fim de tornar a saúde bucal atrativa para ser noticiada, principalmente explorando o potencial educativo jornalístico, para que, dessa forma, atue como um insumo de saúde. Paralelo a isso, as universidades e demais instituições geradoras de conhecimento científico que pretendem valorizar e divulgar suas realizações, bem como auxiliar a construção da cidadania junto à sociedade em que estão inseridas, devem estar atentas às estratégias de comunicação midiática capazes de estimular a reflexão e o contato com os temas científicos para a população, como o investimento em assessorias de imprensa e observatórios de mídia ${ }^{29,30}$.

Os assuntos abordados nas matérias de saúde bucal em ambos os jornais compreenderam desde informações sobre políticas de saúde bucal, serviços prestados à comunidade e prevenção às doenças bucais, os quais configuram os interesses da Saúde Bucal Coletiva, até as "tendências estéticas” do sorriso, divulgação de novas tecnologias, especialidades odontológicas e novas descobertas científicas, as quais se referem à Odontologia de mercado e especializada. É importante que esses conhecimentos sejam capazes de serem confrontados criticamente pela sociedade e se reflitam em projeção e utilidade social ${ }^{31}$. Dessa for- ma, destaca-se a importância do uso de linguagem acessível ao leitor leigo e a explicação dos termos técnicos citados nas publicações, uma vez que, ao invés de alienar e confundir, o jornalismo deve promover a popularização do conhecimento científico e tornar as questões odontológicas compreensíveis e motivadoras para estes leitores. Além disso, é importante destacar que o uso da expressão "cientificamente comprovado" (ou assemelhados) e a citação de dados estatísticos (extraídos algumas vezes de sites não científicos da Internet) não garantem uma informação de qualidade por si só, e uso desse artifício deve ser utilizado com coerência e real embasamento teórico.

As abordagens informativas e educativas das matérias desempenham protagonismo social, enquanto que a abordagem enfatizando o marketing objetiva, majoritariamente, vender produtos e serviços, em especial novos tratamentos e clínicas especializadas. Dessa forma, as matérias de saúde bucal com abordagem classificada em "marketing" despertam desconfiança por parte dos pesquisadores, uma vez que se sabe que na área da saúde bucal e da saúde como um todo, a pesquisa científica e a indústria de produtos e novas tecnologias estão envolvidas, muitas vezes, num lobby para formar uma opinião pública favorável a criação de mercado para um novo produto, ou para ocultar prejuízos a saúde. Assim, os limites entre o marketing e a ciência tornam-se cada vez mais tênues, comprometendo a qualidade da informação ${ }^{21}$. Porém, não se pode tratar a comunicação no campo da saúde bucal coletiva como se fosse uma empresa comercial, onde se trata com clientes, objetiva-se o lucro, a publicidade de marcas e a venda de $\operatorname{produtos}^{32}$.

O jornal A Tribuna destacou-se pela grande veiculação do acesso a tratamentos odontológicos. Percebeu-se nesse periódico, inclusive, que esse tema era muito divulgado na capa do jornal, na maioria das vezes abordado como "dentistas de graça no bairro X”, o que representa a valorização da temática para o público alvo, uma vez que apenas 39\% da população capixaba conta com a cobertura de saúde bucal dentro da Estratégia de Saúde da Família do SUS, e os indivíduos que necessitam de atendimento odontológico públicos, ficam, portanto, a mercê de iniciativas muitas vezes pontuais ou filantrópicas. O jornal A Tribuna priorizou a abordagem à temática estética de "forma educativa" $(73,5 \%)$ enquanto o jornal A Gazeta o fez em apenas 30,8\% das publicações. Mais uma vez, essa diferença pode ser justificada pela disparidade entre os preços dos periódicos (o valor do exemplar de A Gazeta é 
50\% maior do que o de A Tribuna) e dos distintos públicos-alvo que recebem através de uma abordagem mais explicativa e educativa, as informações que lhes são incomuns em seu círculo social. Contudo, cabe ressaltar que, frequentemente, essa abordagem da temática apresenta um viés ideológico, sendo subjacente a essa abordagem educativa, a difusão da valorização e o consumo de procedimentos estéticos.

Essa divisão dos assuntos em diferentes "propostas odontológicas" apresentadas no estudo está relacionada à reflexão de Narvai e Frazão ${ }^{1}$ que diz respeito à disjunção epistemológica da Saúde Bucal Coletiva com a Odontologia de mercado. Isso implica o desenvolvimento de uma práxis que rompe também com a prática odontológica hegemônica, determinando que o trabalho odontológico seja desenvolvido com base nas necessidades da população e que, opondo-se à lógica de mercado, rompa com o status quo caracterizado pela mercantilização dos serviços e pela manutenção do monopólio do acesso aos recursos odontológicos pelas elites.

A mídia estimula os valores dessa prática odontológica hegemônica, ao transformar seu objeto em mercadoria e priorizar a divulgação de matérias com valorização exacerbada à estética e ao consumismo de novas tecnologias, as quais muitas vezes, representam "mais do mesmo", mas com uma conotação de "última moda nos consultórios", a qual fascina o público e atrai as pessoas "em busca do sorriso perfeito". Dessa forma, a práxis odontológica insere-se na era do capitalismo consumista, onde os espaços como a escola, a família e instituições acadêmicas perdem lugar na socialização da cultura de massa odontológica (e a divulgação de valores como "saúde integral" e prevenção), dando lugar para a sedução midiática do consumismo e da exploração estética exagerada ${ }^{33}$.

O predomínio de consulta às fontes especialistas, em detrimento às fontes classistas, de movimentos não governamentais e de cidadãos também foi encontrado em outros estudos ${ }^{34,35}$. Reconhece-se a importância do saber especialista na abordagem das questões relativas à saúde e à saúde bucal e, também, as frequentes dificuldades de interação entre esses profissionais e os jornalistas, o que leva, muitas vezes, à referência repetitiva aos mesmos profissionais (os mais acessíveis) na abordagem de determinados assuntos de sua competência. Reflete-se, entretanto, que os valores nas escolhas destes especialistas não podem estar relacionados a uma motivação de exibição narcísica e de promoção pessoal através da mí- dia, mas sim em critérios de competência profissional e de relevância pública. Além disso, em uma sociedade democrática, na qual há conflitos de interesses e diferentes opiniões públicas, é importante que as matérias tragam as mais diversas reflexões e pontos de vista possíveis, para que a agenda pública em saúde bucal não seja monopolizada por uma só perspectiva, ou ainda, seja manipulada por interesses mercadológicos, os quais usam, muitas vezes, de métodos espúrios para fazer veicular informações de seu interesse ou para manipular a opinião pública ${ }^{36,37}$. Além disso, o pluralismo de fontes faz-se necessário para garantir a expressão dos mais diversos discursos sobre a temática, inclusive de opiniões divergentes, e não apenas a opinião hegemônica.

\section{Conclusão}

Os resultados do estudo evidenciaram que a distribuição temporal das matérias não apresentou um padrão definido, caracterizando uma abordagem episódica da temática. Houve um predomínio de páginas pares, veiculação em página inteira e poucas chamadas na capa, o que significa uma valorização moderada da temática. Constatou-se um vasto quantitativo de matérias, porém, na hierarquização jornalística, elas mostramse menos valorizadas. Também foi constatado que os projetos editoriais diferentes, aliados à diferença de público alvo, determinaram o padrão jornalístico de noticiabilidade de saúde bucal.

A existência de uma editoria de saúde aos domingos no jornal A Gazeta chamou a atenção pela concentração de notícias nesse dia. Porém, essa iniciativa transformou-se em uma revista de generalidades (Revista AG), que embora possua indícios de que seja mais vantajosa comercialmente para o jornal, diminuiu a publicação e o aprofundamento das questões de saúde bucal, representando uma perda na qualidade das publicações.

Evidenciou-se a necessidade de uma maior valorização das iniciativas capixabas de saúde bucal, principalmente relacionadas à pesquisa, propiciando um maior diálogo entre mídia, instituições de pesquisa e sociedade. Paralelamente, o predomínio de fonte especialista ressalta a necessidade de se exigir o pluralismo de vozes na divulgação dos temas de saúde bucal, propiciando, assim, a garantia da consideração dos diversos interesses da sociedade referentes ao assunto.

Admite-se que a disjunção entre os critérios valorativos da comunicação e saúde e os interesses jornalísticos, como preconizado por Eps- 
tein $^{28}$, é real, uma vez que aquilo que interessa ao jornalismo é o extraordinário e o inusitado, ao passo que o relevante para a comunicação em saúde é o discurso preventivista e promotor de saúde, ordinários do dia a dia. Entretanto, percebeu-se no estudo que, apesar das matérias de saúde bucal, na maioria das vezes, não apresentarem "furos" jornalísticos, podem ser trabalhadas (através de uma prática jornalística consciente) de maneira a evocar o extraordinário do ordinário, dando origem a matérias com relevância social em ambos os periódicos.

A despeito do relatado em outros estudos ${ }^{14,15}$, a presente pesquisa evidenciou um grande nú- mero de assuntos abordados de forma educativa, tanto relacionados à Saúde Bucal Coletiva (quatro em ambos os jornais) quanto à Odontologia de mercado (sete em A Tribuna e cinco em A Gazeta), o que é um fator relevante para a atuação da mídia na promoção da saúde bucal. Entretanto, ressalta-se a importância de se avaliar criticamente as idéias subjacentes a essa proposta educativa, para que um estímulo ao consumo de produtos ou um discurso "culpabilizante" e "responsabilizante" do indivíduo pela sua saúde não sejam veiculados descontextualizadamente para a população, comprometendo a atuação da mídia como um insumo de saúde bucal.

\section{Colaboradores}

AG Cavaca participou da coleta, análise e interpretação dos dados e do delineamento e redação do artigo. V Gentilli participou da análise e interpretação dos dados e do delineamento, revisão crítica e aprovação da versão final do artigo. E Zandonade participou da análise estatística e interpretação dos dados e na revisão crítica e aprovação da versão final do artigo. M Cortellete Júnior participou da coleta de dados, revisão crítica e aprovação da versão final do artigo. A Emmerich participou da análise e da interpretação dos dados, revisão crítica e aprovação da versão final do artigo.

\section{Agradecimentos}

Ao professor Elias Oliveira pela colaboração neste estudo através do desenvolvimento do sistema de coleta de dados utilizado, ao Observatório de Mídia Regional pela parceria no estudo e à Capes pelo financiamento de bolsa de estudos de Mestrado de AG Cavaca.

\section{Referências}

1. Narvai PC, Frazão P. Saúde Bucal no Brasil: muito além do céu da boca. Rio de Janeiro: Fiocruz; 2008.

2. Chaves MM. Odontologia social. 3a ed. São Paulo: Artes Médicas; 1986.

3. Oliveira VC. Mídia, controle público e cidadania. In: Santos A. Caderno Mídia e Saúde Pública: Comunicação em Saúde pela Paz, v. 2. Belo Horizonte: ESP-MG; 2007. p. 71-79.

4. Brasil. Ministério da Saúde. Pesquisa Nacional de Saúde Bucal - BS Brasil 2010. Brasília. 2011 [site na Internet]. [acessado 2011 jan 7]. Disponível em: http://189.28.128.100/dab/docs/geral/apresentacao_ SB2010.pdf

5. Narvai PC. Odontologia e Saúde Bucal Coletiva. 2a ed. São Paulo: Santos; 2002.

6. Bastos JRM, Peres SHCS, Ramires I. Educação para a saúde. In: Pereira AC. Odontologia em saúde coletiva: planejando ações e promovendo saúde. Porto Alegre: Artmed; 2003.

7. Carvalho MB, Bicudo Pereira IMT. O jornal e a educação em saúde bucal. Rev. bras. Saúde esc 1994; 3(1-4):39-43.

8. Gentilli V. Democracia de massas: jornalismo e cidadania. Porto Alegre: EDIPUCRS; 2005.

9. Wolf M. Teorias da Comunicação. 5a ed. Lisboa: Editorial Presença, 1999.

10. Epstein I. Quando um fato se transforma em notícia no jornalismo e na ciência. Comunicação \& Sociedade 2007; 47:159-179.

11. Jornal A Tribuna. Histórico. [acessado 2011 jan 14]. Disponível em: http://www.tribunaonline.com.br

12. A Gazeta. Histórico. [acessado em 2001 jan 14]; Disponível em: http://gazetaonline.globo.com/index. php?id=/redegazeta/midias

13. Tito A, Santana JC, Tarcísio J. A Trajetória dos Meios de Comunicação Capixabas. In: Martinuzzo JA, organizador. Quase 200. Vitória: DIO; 2008. p. 37-54. 
14. Sinhorini PA, Garbin CAS, Oliveira RN. O caráter educativo de artigos relacionados à odontologia selecionados da mídia voltada ao público em geral. Revista Paulista de Odontologia 2005; 27(3):11-13.

15. Noguerol B, Follana M, Sicilia A, Sanz M. Analysis of oral health information in the Spanish mass media. Community Dent Oral Epidemiol 1992; 20(1):1519.

16. Brasil. Ministério da Saúde (MS). Diretrizes da Política Nacional de Saúde Bucal. Brasília: MS; 2004.

17. Azevedo L, Ramiro TB, Monteiro V, Teixeira S, Oliveira E. Recuperação de informação através do processo de aproximações sucessivas. In: Anais do XXI Congresso brasileiro de biblioteconomia, documentação e ciência da informação, 2005; Curitiba.

18. Bardin L. Análise de Conteúdo. Portugal: Edições 70; 2009.

19. Herscovitz HG. Análise de Conteúdo em Jornalismo. In: Lago C, Benetti M. Metodologia de Pesquisa em Jornalismo. Petrópolis: Vozes; 2007.

20. Gentilli V. O futuro do jornalismo: democracia, conhecimento, esclarecimento. In: Christofoletti R, Motta LG, organizadores. Observatórios de mídia: olhares da cidadania. São Paulo: Paulus; 2008.

21. Luiz OC. Ciência e risco nos jornais diários. São Paulo, São Bernardo do Campo: Nablume, Cesco; 2006.

22. Fausto Neto A. Percepções acerca dos campos da Saúde e da Comunicação. In: Pitta AMR, organizador. Saúde \& Comunicação: visibilidades e silêncios. São Paulo, Rio de Janeiro: Abrasco, Hucitec; 1995. p. 267-293.

23. Nutbeam D. Health promotion glossary. Genebra: World Health Organization; 1998.

24. World Health Organization (WHO) (Amro/Paho). Communication, Education ans participation: a framework ans guide to action. Washington: WHO; 1996.

25. Massuchin MG, Cervi EU. As políticas públicas ambientais no jornal Gazeta do Povo: Como se dá a cobertura das ações governamentais para o meio ambiente. Estudos em jornalismo e mídia 2010; 7(12): 318-331.

26. Brasil. Ministério do Orçamento e Gestão. Instituto Brasileiro de Geografia e Estatística. Pesquisa Nacional por Amostra de Domicílios: acesso e utilização de serviços de saúde 2003. Rio de Janeiro: IBGE; 2005.

27. Burkett W. Jornalismo científico: como escrever sobre ciência, medicina e alta tecnologia para os meios de comunicação. Rio de Janeiro: Forense Universitária; 1990.

28. Epstein I. Comunicação de massa para a saúde: esboço de uma agenda midiática. Revista latinoamericana de Ciências de La comunicación 2008; 5(89):132-142.
29. Rosa SHS. A produção científica da UNESP de Botucatu e a mídia impressa local: um estudo de caso. In: Congresso Multidisciplinar de Comunicação para o Desenvolvimento Regional - UNESCOM; 2006; São Bernardo do Campo. [acessado 2011 jan 11]. Disponível em: http://encipecom.metodista.br/ mediawiki/index.php/A_produ $\%$ C3\%A $7 \%$ C $3 \%$ A3o_cient $\%$ C3\%ADfica_da_Unesp_de_Botucatu_ e_a_m\%C3\%ADdia_impressa_local:_um_estudo_de_caso

30. Rebouças E, Cunha P. Observatórios de mídia como instrumentos para (da) democracia. RECIIS-Revista eletrônica de Com. Inf. Inov. Saúde 2010; 4(4):85-93.

31. Marques De Melo J. Teoria do jornalismo: identidades brasileiras. São Paulo: Paulus; 2006.

32. Araújo IS, Cardoso JM. Comunicação e Saúde. Rio de Janeiro: Editora Fiocruz; 2007.

33. Emmerich A, Castiel LD. Jesus tem dentes metalfree no país dos banguelas?: odontologia dos desejos e das vaidades. História, Ciências, Saúde - Manguinhos 2009; 16(1):95-107.

34. França E, Abreu D, Siqueira M. Epidemias de dengue e divulgação de informações pela imprensa. Cad Saude Publica 2004; 20(5):1334-1341.

35. Lacerda AE, Mastroiani FC, Noto AR. Tabaco na mídia: análise de matérias jornalísticas no ano de 2006. Cien Saude Colet 2010; 15(3):725-731.

36. Canela G. A cobertura sobre saúde relativa à infância e à adolescência: uma análise comparativa do material veiculado por 50 jornais brasileiros. In: Santos A, organizador. Caderno Mídia e Saúde Pública. Belo Horizonte: Escola de saúde pública/FUNED; 2006. p. 57-69.

37. Bueno WC. A cobertura de saúde na mídia brasileira: Os sintomas de uma doença anunciada. Comunicação \& Sociedade 2001; 22(35):187-210.

Artigo apresentado em 23/03/2011

Aprovado em 08/05/2011

Versão final apresentada em 13/05/2011 